\title{
Song repertoires and sensory exploitation: reconsidering the case of the common grackle
}

\author{
DAVID A. GRAY \& JULIE C. HAGELIN \\ Department of Biology, The University of New Mexico \\ (Received 14 July 1995; initial acceptance 11 October 1995; \\ final acceptance 29 January 1996; MS. number: A7363)
}

\begin{abstract}
Male common grackles, Quiscalus quiscula, sing one song type each, yet females prefer multiple songs. A pre-existing sensory bias explanation has been proposed to account for these results. Using phylogenetic analysis and published behavioural studies, (1) it is shown that the single-song condition of males is likely to be the derived state, and (2) it is suggested that female common grackles' preference for multiple songs may not be surprising given their natural history, and may in fact be a functional preference. The idea that the female preference is also ancestral and serves no current function, however, cannot be ruled out.

(C) 1996 The Association for the Study of Animal Behaviour
\end{abstract}

As part of an ongoing research programme designed to explain the function(s) of male songbird repertoires, Searcy (1992) found that female common grackles prefer tapes of male song constructed to contain a repertoire of four songs over a tape playing a single song. In the wild, male common grackles do not have complex repertoires; each individual sings only one song type (Wiley 1976c; Searcy 1992). Because individual male common grackles sing only one song type, Searcy proposed that his results are consistent with pre-existing bias models of sexual selection (Ryan \& Keddy-Hector 1992; Ryan \& Rand 1993). Pre-existing bias models propose that the evolution of certain male ornamental traits can be explained by features of female nervous systems that predisposed females to respond more strongly to certain male characteristics; i.e. male traits evolved in response to the selection pressure imposed by an already existing female preference. The essence of the pre-existing sensory bias model is that the female bias precedes the development of the male trait. Phylogenetic studies have been used to both demonstrate and falsify the pre-existence of the female bias (Basolo 1990; Hill 1994).

The sensory bias that Searcy identified involves the habituation of nervous system response to a repeated specific stimulus (Krebs 1976;

Correspondence: D. A. Gray, Department of Biology, 167 Castetter Hall, University of New Mexico, Albuquerque, NM 87131, U.S.A.
Petrinovich 1984). Habituation is the diminishing of the response to a specific stimulus with repeated presentation of that stimulus. The diminishing response shows 'recovery' when a different stimulus is presented. Consistent with Searcy's interpretation, female common grackles showed a decreased response to a repeated single song and an increased response when male song types were switched. Based on phylogenetic analysis and a review of published behavioural studies, however, we suggest (1) that the single-song-per-male condition of common grackles is derived from an ancestral state with song repertoires, and (2) that the female preference demonstrated by Searcy can be interpreted within the context of the natural history of common grackles, and may have a current functional basis. We do not attempt to discredit the hypothesis that songbird repertoires may have evolved to exploit the neural patterns of habituation to specific stimuli. In our view, sufficient information to test this broad hypothesis does not yet exist.

\section{Song Repertoires and Phylogenetic History}

The sensory bias model requires that the female preference predates the male trait. Phylogenetic tests can help establish whether the preference preceded the trait or whether the trait and preference coevolved. If the female preference is found in an ancestral species that lacks the male trait, then the preference probably predated the trait. 
Table I. Icterid species with repertoire data and references*

\begin{tabular}{lll}
\hline Common Name & \multicolumn{1}{c}{ Scientific Name } & \multicolumn{1}{c}{ Reference } \\
\hline Eastern meadowlark & Sturnella magna & (Falls \& D'Agincourt 1982) \\
Western meadowlark & Sturnella neglecta & (Falls \& D'Agincourt 1982) \\
Peruvian red-breasted meadowlark & Sturnella bellicosa & (Gochfeld, in Irwin 1990) \\
Long-tailed meadowlark & Sturnella loyca & (Gochfeld, in Irwin 1990) \\
Lesser red-breasted meadowlark & Sturnella defilippi & (Gochfeld, in Irwin 1990) \\
Bonaparte's blackbird & Sturnella superciliaris & (Irwin 1990) \\
Yellow-winged blackbird & Agelaius thilius & (Irwin 1990) \\
Red-winged blackbird & Agelaius phoeniceus & (Yasukawa et al. 1980) \\
Brown-headed cowbird & Molothrus ater & (Dufty 1985; Dufty 1986) \\
Bay-winged cowbird & Molothrus badius & (Irwin 1990) \\
Brewer's blackbird & Euphagus cyanocephalus & (Irwin 1990) \\
Bobolink & Dolichonyx oryzivorous & (Capp 1992) \\
Northern oriole & Icterus galbula & (Beletsky, in Irwin 1990) \\
Yellow-rumped cacique & Cacicus cela & (Trainer 1989) \\
Scarlet-rumped cacique & Cacicus uropygialis & (Irwin 1990) \\
Common grackle & Quiscalus quiscula & (Wiley 1976c) \\
Great-tailed grackle & Quiscalus major & (Selander \& Giller 1961; Irwin 1990) \\
Boat-tailed grackle & Quiscalus mexicanus & (Selander \& Giller 1961) \\
\hline
\end{tabular}

*No icterids without repertoires other than the common grackle were encountered.

For example, Basolo (1990) mapped female preferences for swords in swordtail fish, Xiphophorus species, onto a phylogeny, and found that ancestral species, without swords, none the less had females that preferred swords (but see Meyer et al. 1994).

The sensory bias hypothesis can also be tested by phylogenetic mapping of the male trait. The male trait may be absent in the derived species but present in the ancestral species. If females of the derived species still prefer the ancestral male trait, the preference may simply be a phyletic holdover from previous times. If a female preference is a phyletic holdover, then this suggests that the preference is not costly, has a current function, or has had insufficient time to be lost.

To test whether female preference in common grackles for male repertoires may be ancestral, we mapped repertoires as a presence/absence character on a composite phylogeny of icterids. The phylogeny used here specifically tests the hypothesis that the single-song-per-male condition of the common grackle is derived from an ancestral condition of repertoires. We only included species with repertoire data. Songbird repertoires have a great deal of variation (e.g. Read \& Weary 1990, 1992). Repertoires are frequently described as 'song type' or 'syllable type' depending on the complexity of the repeated elements. In our analysis, we treat repertoires as a presence/absence character. By doing so, we assume that the evolutionary transitions of interest are between having and not having a repertoire ('song type' or 'syllable type'), and that habituation and stimulus specificity apply equally to 'song type' and 'syllable type' repertoires.

No complete phylogeny exists for all of the species for which we were able to obtain repertoire data. We consulted several sources to construct the phylogeny we use (Smith \& Zimmerman 1976; Hobart et al. 1982; Sibley \& Ahlquist 1990; Björklund 1991; Lanyon 1992, 1994; Webster 1992). For the species for which we have repertoire data (Table I), the phylogeny is in most respects the same as that used by Irwin (1994) based on mitochondrial sequence data work by Lanyon (1992, 1994). We added four species of Sturnella to the branch containing S. magna and S. loyca without resolving any relationships. In doing so, we follow traditional taxonomy only and assume that Sturnella forms a monophyletic group. Quiscalus major is placed with congeners on the basis of traditional taxonomy and the morphological phylogeny given by Björklund (1991). Cacicus uropygialis is considered the closest relative of C. cela based on traditional taxonomy (see also Irwin 1994). Molothrus badius is placed with M. ater. This may be the most 


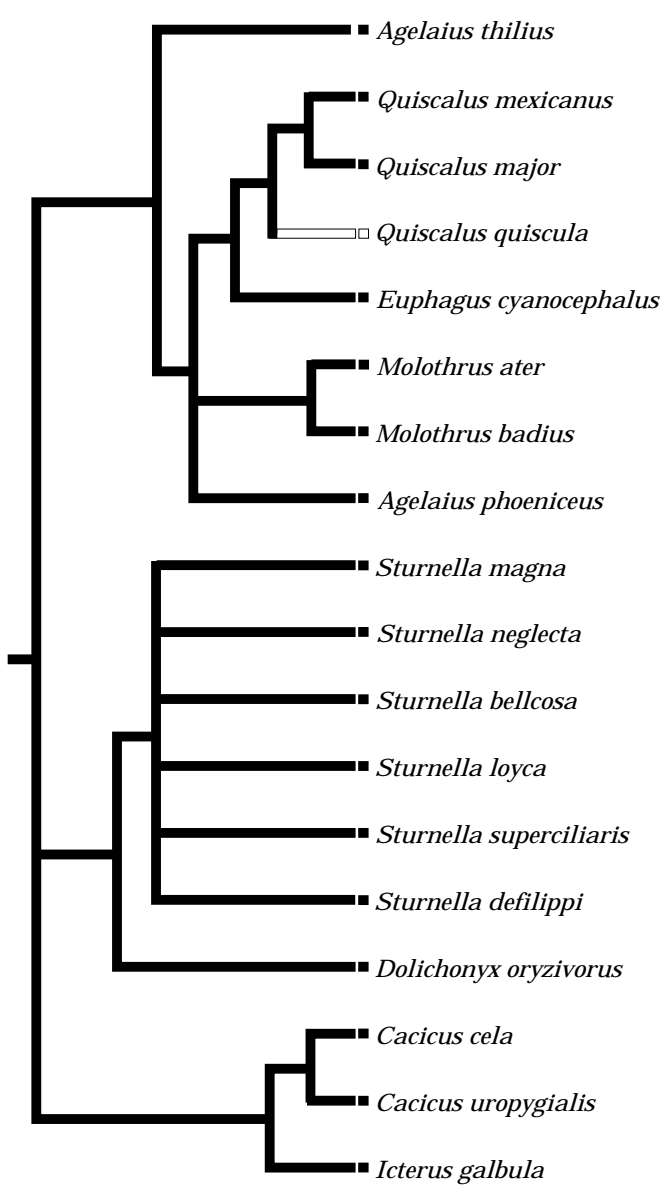

Figure 1. Phylogeny of icterids with repertoire data listed in Table I. Repertoires are mapped as a presence/absence character. Dark bars represent species and ancestral states with repertoires, open bar represent species and ancestral states without repertoires. The phylogeny follows Lanyon (1994) with additions and modifications as noted in the text. Ancestral character state reconstruction was done using MacClade (Maddison \& Maddison 1989).

suspect of the phylogenetic assumptions we make, because Lanyon (1992), using mitochondrial DNA, found no evidence either supporting or refuting this relationship.

All icterids considered in our analysis have repertoires except the common grackle. Character analysis using MacClade (Maddison \& Maddison 1989) strongly suggests that repertoires are ancestral within this clade, and that the common grackle has lost this trait (Fig. 1). No alternative phylogenetic hypothesis for these species alters our conclusion. Even placement of common grackles ancestral to all other species (which is not supported by any of the phylogenies above) does not result in an ancestral state without song repertoires; it gives an equivocal result for the ancestral state. An equivocal result means that there is no single most parsimonious reconstruction of the ancestral state.

\section{DISCUSSION AND CONCLUSIONS}

\section{Common Grackles}

The phylogenetic analysis indicates that male common grackles have lost repertoires. Ancestral males appear to have had repertoires; whether ancestral females preferred them, we do not know. Female common grackles, however, appear to respond more strongly to multiple songs presented sequentially (Searcy 1992). This situation leaves unresolved the question of the function, if any, of the apparent female preference. The female preference may date from a time when ancestral grackles did have song repertoires and has persisted in evolutionary time without any benefits or reinforcement. If so, the preference should have little cost associated with it (i.e. mutant females without the preference gain little or no advantage). This hypothesis would require the female preference to be inexpensive. Growing evidence suggests that repertoires involve costs for males (DeVoogd et al. 1993); however, the cost of the preference to females is unknown. Given our uncertainty about the cost of the female preference, we cannot dismiss the possibility that the preference is entirely non-functional.

The female preference may serve some current function. Both social selection and sexual selection could favour increased female responsiveness to multiple males. Common grackles are socially monogamous, non-territorial breeders, which nest in and around loose colonies (Wiley 1976a, b, c). Pair formation takes place at singing assemblages and during 'group flights' in which typically one female departs the singing assemblage and is followed by several males (Wiley 1976a). Singing assemblages contain from 3 to 20 individuals. Multiple individuals sing concurrently, although sequential singing also occurs (Wiley 1976a). Individuals do sing alone, but 'usually not for long' (Wiley 1976a, page 63). 
In Searcy's study (Searcy 1992), females may have responded more strongly to sequentially presented male songs simply because multiple song auditory stimulus is the natural state. That is, Searcy assumed that the single-song tape best represents the natural stimulus set and that a composite tape of multiple songs represents a novel, experimental stimulus set. Although individual males sing only one song type each, the validity of this assumption is suspect. The experimental design does not eliminate the possibility that females responded more strongly to the perception of multiple males than to the perception of a single male. That is, females may actively prefer multiple songs because, in nature, multiple songs are reliably associated with multiple males. If female response serves to incite male-male competition (Cox \& LeBoeuf 1977), then a female that responds more strongly to stimuli from several males may gain information about male quality that is relevant to her mating decision. In this light, it is particularly interesting to note that the 'group flights' are usually led by a single female with several males following or giving chase (Wiley 1976a). Wiley also notes (page 64) that the group flights 'were extensions of the activity in singing groups'. Multiple male groups may also reduce the time (and thus the cost) of female choice.

We therefore suggest the following alternative explanations for the occurrence of a positive response of female common grackles to song repertoires, despite the fact that males do not have song repertoires: (1) the preference is nonfunctional (a) because it has been maintained from a time when ancestral grackles did have song repertoires, and it is not a costly preference, or (b) the loss of male repertoires is so recent that the female preference for repertoires has not had time to be lost; (2) the preference is functional and serves to provoke male-male competition, which may lead to information, benefiting the female, about male quality.

\section{Song Repertoires and Sensory Bias}

We have argued that the application of sensory bias ideas to common grackles, via habituation and stimulus specificity, ignores phylogenetic history and possible current function related to breeding ecology. Searcy et al. (1994) include phylogenetic history in their discussion of sensory bias and repertoires, but only to the extent that the bias may help maintain repertoires if the repertoires are ancestral. In common grackles at least, the bias (if pre-existing) has been insufficient to maintain repertoires. Similarly, Irwin (1988) studied the phylogeny and development of song in sparrows and found it more parsimonious to conclude that repertoires were ancestral and have been lost in the Zonotrichia lineage. Female whitethroated sparrows, Z. albicollis, do not prefer repertoires, yet show the same pattern of habituation that other species do. Here again, a sensory bias appears insufficient to have maintained repertoires. In fact, because these Zonotrichia sparrows show the habituation pattern but not the preference, the preference and the habituation pattern appear to be distinct and can be decoupled.

We emphasize that this conclusion is not a dismissal of the very intriguing possibility that Searcy (1992) raises. Evidence in favour of the hypothesis that habituation and stimulus specificity promotes the subsequent evolution of repertoires comes primarily from a decrease in female response to repeated song and an increase in female response when song types are switched. These results occur in species with repertoires, such as red-winged blackbirds, Agelaius phoeniceus, and swamp sparrows, Melospiza georgiana. It also occurs in species without repertoires and may or may not be associated with a female preference for repertoires. Female field sparrows, Spizella pusilla, and white-throated sparrows, Z. albicollis, show an increased response to male repertoires but no preference for them. An increased female response to male repertoires also occurs in the common grackle, Q. quiscula, a species lacking male repertoires. Unlike the sparrow examples above, however, female common grackles also show a preference for male repertoires (reviewed in Searcy 1992). Testing the habituation/stimulus specificity hypothesis will require proper phylogenetic tests to determine when repertoires originated.

Even more important, we need to assess the potential of 'bias' as an evolutionary force. Variability between species in both repertoires and female responsiveness to repertoires should be explained. This variability leads us to suspect that, although a general sensory bias favouring repertoires may exist, it may be (1) insufficient to maintain repertoires if they are ancestral, and (2) 
would not explain the range of variation found in passerines. If habituation and stimulus specificity are general features of sensory systems, which they appear to be, then unless the bias is itself subject to directional evolution, we see no reason to suppose that the strength of the bias will systematically covary with the complexity of the repertoires. All of these ideas would benefit from further research on both the phylogenetic history and possible function of female preferences for repertoires.

\section{ACKNOWLEDGMENTS}

We thank J. D. Ligon and the UNM Biology Avian Social Systems group for valuable discussion. W. Searcy, R. Irwin and an anonymous referee provided us with thoughtful and constructive comments. Both D.A.G. and J.C.H. are supported by NSF Pre-doctoral Fellowships.

\section{REFERENCES}

Basolo, A. L. 1990. Female preference predates the evolution of the sword in swordtail fish. Science, 250, 808-810.

Björklund, M. 1991. Evolution, phylogeny, sexual dimorphism and mating system in the grackles (Quiscalus spp.: Icterinae). Evolution, 45, 608-621.

Capp, M. S. 1992. Tests of the function of the song repertoire in bobolinks. Condor, 94, 468-479.

Cox, C. R. \& LeBoeuf, B. J. 1977. Female incitation of male competition: a mechanism in sexual selection. Am. Nat., 111, 317-335.

DeVoogd, T. J., Krebs, J. R., Healy, S. D. \& Purvis, A. 1993. Relations between song repertoire size and the volume of brain nuclei related to song: comparative evolutionary analyses amongst oscine birds. Proc. $R$. Soc. Lond. Ser. B, 254, 75-82.

Dufty, A. M., Jr. 1985. Song sharing in the brownheaded cowbird (Molothrus ater). Z. Tierpsychol., 69, 177-190.

Dufty, A. M., Jr. 1986. Singing and the establishment and maintenance of dominance hierarchies in captive brown-headed cowbirds. Behav. Ecol. Sociobiol., 19, 49-55.

Falls, J. B. \& D'Agincourt, L. G. 1982. Why do meadowlarks switch song types? Can. J. Zool., 60, 34003408 .

Hill, G. E. 1994. Geographic variation in male ornamentation and female preferences in the house finch: a comparative test of models of sexual selection. Behav. Ecol., 5, 64-73.

Hobart, H. H., Gunn, S. J. \& Bickham, J. W. 1982. Karyotypes of six species of North American blackbirds (Icteridae: Passeriformes). Auk, 99, 514 518.

Irwin, R. E. 1988. The evolutionary importance of behavioural development: the ontogeny and phylogeny of bird song. Anim. Behav., 36, 814-824.

Irwin, R. E. 1990. Directional sexual selection cannot explain variation in song repertoire size in the New World blackbirds (Icterinae). Ethology, 85, 212224.

Irwin, R. E. 1994. The evolution of plumage dichromatism in the New World blackbirds: social selection on female brightness? Am. Nat., 144, 890-907.

Krebs, J. R. 1976. Habituation and song repertoires in the great tit. Behav. Ecol. Sociobiol., 1, 215-227.

Lanyon, S. M. 1992. Interspecific brood parasitism in blackbirds (Icterinae): a phylogenetic approach. Science, 255, 77-79.

Lanyon, S. M. 1994. Polyphyly of the blackbird genus Agelaius and the importance of assumptions of monophyly in comparative studies. Evolution, 48, 679-693.

Maddison, W. P. \& Maddison, D. R. 1989. Interactive analysis of phylogeny and character evolution using the computer program MacClade. Folia Primatol., 53, 190-202.

Meyer, A., Morrissey, J. M. \& Schartl, M. 1994. Recurrent origin of a sexually selected trait in Xiphophorus fishes inferred from a molecular phylogeny. Nature, Lond., 368, 539-542.

Petrinovich, L. 1984. A two-factor dual-process theory of habituation and sensitization. In: Habituation, Sensitization, and Behavior (Ed. by H. V. S. Peeke \& L. Petrinovich), pp. 17-55. Orlando, Florida: Academic Press.

Read, A. F. \& Weary, D. M. 1990. Sexual selection and the evolution of bird song: a test of the Hamilton-Zuk hypothesis. Behav. Ecol. Sociobiol., 26, 47-56.

Read, A. F. \& Weary, D. M. 1992. The evolution of bird song: comparative analyses. Proc. R. Soc. Lond. Ser. $B, 338,165-187$.

Ryan, M. J. \& Keddy-Hector, A. 1992. Directional patterns of female mate choice and the role of sensory biases. Am. Nat., 139, S4-S35.

Ryan, M. J. \& Rand, A. S. 1993. Sexual selection and signal evolution: the ghost of biases past. Proc. $R$. Soc. Lond. Ser. B, 340, 187-195.

Searcy, W. A. 1992. Song repertoire and mate choice in birds. Am. Zool., 32, 71-80.

Searcy, W. A., Coffman, S. \& Raikow, D. F. 1994. Habituation, recovery and the similarity of song types within repertoires in red-winged blackbirds (Agelaius phoeniceus) (Aves, Emberizidae). Ethology, 98, 38-49.

Selander, R. K. \& Giller, D. R. 1961. Analysis of sympatry of great-tailed and boat-tailed grackles. Condor, 63, 29-86.

Sibley, C. G. \& Ahlquist, J. E. 1990. Phylogeny and Classification of Birds: A Study in Molecular Evolution. New Haven, Connecticut: Yale University Press.

Smith, J. K. \& Zimmerman, E. G. 1976. Biochemical genetics and evolution of North American blackbirds, family Icteridae. Comp. Biochem. Physiol., 53B, 319324. 
Trainer, J. M. 1989. Cultural evolution in song dialects of yellow-rumped caciques in Panama. Ethology, 80, 190-204.

Webster, M. S. 1992. Sexual dimorphism, mating system and body size in New World blackbirds (Icterinae). Evolution, 46, 1621-1641.

Wiley, R. H. 1976a. Affiliation between the sexes in common grackles I. Specificity and seasonal progression. Z. Tierpsychol., 40, 59-79.
Wiley, R. H. 1976b. Affiliation between the sexes in common grackles II. Spatial and vocal coordination. Z. Tierpsychol., 40, 244-264.

Wiley, R. H. 1976c. Communication and spatial relationships in a colony of common grackles. Anim. Behav., 24, 570-584.

Yasukawa, K., Blank, J. L. \& Patterson, C. B. 1980. Song repertoires and sexual selection in the redwinged blackbird. Behav. Ecol. Sociobiol., 7, 233-238. 